\title{
LEGUMINOSAS DE VERÃO: CAPACIDADE PARA FIXAÇÃO SIMBIÓTICA DE NITROGÊNIO E POTENCIAL DE UTILIZAÇÃO NO SUL DO BRASIL
}

\author{
SUMMER LEGUMES: SYMBIOTIC NITROGEN FIXATION ABILITY AND \\ UTILIZATION POTENTIAL IN SOUTH BRAZIL
}

Milton Antonio Seganfredo

\section{- REVISÃO BIBLIOGRÁFICA -}

\section{RESUMO}

As condições climáticas predominantemente subtropicais no Sul do Brasil fazem do cultivo de leguminosas de verão, uma opção para a alimentação animal e programas de manejo do solo. Estas plantas podem promover a melhoria gradual das características químicas, físicas e biologicas do solo e, também, ser uma fonte de proteína a baixo custo para a alimentação animal, devido a sua capacidade para fixação simbiótica de nitrogênio. Com a diversificação de espécies, expansão da área cultivada e o desenvolvimento de novos genótipos, diversas espécies e cultivares tem apresentado simbiose deficiente não apenas com estirpes nativas, mas também com aquelas já selecionadas. Para o suprimento de inoculantes específicos a cada leguminosa e local de interesse, deve-se proceder o isolamento de novas estirpes paralelamente com a seleção contínua das estirpes já existentes em bancos de germoplasma, nas novas cultivares geneticamente melhoradas.

Palavras-chave: leguminosas de verão, simbiose, especificidade, manejo do solo.

\section{SUMMARY}

The predominance of subtropical climatic condition in the Southern Brazil, makes the summer legumes cultivation in this region an option for animal feeding and soil management programs. These plants can gradually improve the chemical, physical and biological soil conditions as well as being a low cost protein source due to its symbiotic nitrogem fixation ability. Due to the potential species arising, to the expansion of the legume cultivated areas and to the new genotype released, several species and even cultivars have showed defficient symbiosis, using both native and early selected rhizobia as inoculants. So, in order to meet rhizobia requirements of each legume in each place, new rhizobia strains should be selected from native populations and the available stocks should be continuously screened against the newly released legume cultivars.

Key words: summer legumes, symbiosis, specificity, soil management.

\section{INTRODUÇÃO}

O manejo inadequado e a baixa fertilidade natural do solo, estão entre os principais fatores limitantes à produtividade de pastagens e de muitas das principais culturas exploradas em regiões de clima tropical e subtropical. Somando-se a isto a baixa disponibilidade de capital por parte dos agricultores para o investimento em insumos agrícolas, torna ainda maior a necessidade de pesquisas buscando alternativas de baixo custo para retardar o declínio da fertilidade e recuperar e/ou manter a capacidade produtiva do solo (CIAT, 1980).

\footnotetext{
${ }^{1}$ Engenheiro Agrónomo, MSc. EMBRAPA, Centro Nacional de Pesquisa de Suínos e Aves CNPSA, Caixa Postal 21, 89700-000, Concórdia, SC. 
A situação acima descrita também é observada no Sul do Brasil, onde o clima subtropical é predominante. Para estas condiçбes o cultivo de leguminosas, apropriadas para cada propósito, pode ser uma alternativa para a melhoria gradual das características químicas, físicas e biologicas do solo e, também, na alimentação animal como fonte de proteína de baixo custo, pelo aproveitamento do nitrogênio fixado pela simbiose destas plantas com bactérias do gênero Rhizobium/Bradyrhizobium (MIYASAKA, 1984; SANTA CATARINA, 1986; CIAT, 1980).

\section{UTILIDADE DAS LEGUMISOSAS DE VERÃO}

\section{Melhoria do solo}

Além do seu emprego em rotação de culturas, cobertura morta ou prática vegetativa de controle a erosão, as leguminosas podem aumentar a atividade microbiana no solo em razão da sua alta proporção de compostos nitrogenados, os quais possibilitam maior eficiência na transformação da massa vegetal acrescida ao solo (MIYASAKA, 1984; MAZUCHOWSKI \& DERPSCH, 1984).

Apesar de não solucionar totalmente os problemas de deficiências minerais no solo, como aponta MIYASAKA (1984), as leguminosas usadas como adubo verde podem aumentar a concentração de $\mathrm{P}, \mathrm{K}, \mathrm{Ca}, \mathrm{Mg}$ e $\mathrm{S}$ da camada superficial, pela sua alta proporção destes elementos. Isto e possivel devido ao seu sistema radicular profundo e bastante ramificado, capaz de extrair estes nutrientes das camadas subsuperficiais, colocando-os à disposição de outras culturas através do processo de reciclagem (FRANCO \& SOUTO, 1984). Algumas leguminosas, como o siratro e guandu, possuem sistema radicular capaz de romper camadas compactadas pelo tráfego de máquinas e implementos agrícolas, contribuindo, desta forma, para a melhoria da estrutura e, em conseqüência, do fluxo de água no solo (PRIMAVESI, 1985; DALLA ROSA, 1981; BOGDAN, 1977).

Avaliando a performance de leguminosas de verão para a proteção do solo contra a erosão em região próxima ao litoral de Santa Catarina, AMADO et al. (1986) observaram que várias espécies atingiram índices de cobertura entre 90 e $100 \%$, com algumas cobrindo $50 \%$ da superfície já aos 38 dias. Na mesma região, AMADO \& ALMEIDA (1987), verificaram que a produção média de leguminosas usadas como adubo verde foi de 41tha de matéria verde e 229 $\mathrm{kg} / \mathrm{ha}$ de nitrogênio para espécies anuais e $36 \mathrm{tha}$ e $257 \mathrm{~kg} / \mathrm{ha}$ de matéria verde e nitrogênio, para espécies perenes (Tabela 1).

\section{Alimentação animal}

Com o contínuo aumento da população, as leguminosas são uma excelente opção para o suprimento de nitrogênio a ser transformado em proteína, principalmente por ruminantes, visando a suprir em carne e leite os mercados consumidores. Isto seria de grande importância para a população de menor poder aquisitivo, uma vez que a produção atual é insuficiente para atender a cota mínima por habitante definida pela FAO (Organização das Naçð̃es Unidas para a Alimentação e Agricultura) (INSTITUTO ..., 1987).

Tabela 1 - Acúmulo de matéria verde e nitrogênio ( $\mathrm{kg} / \mathrm{ha}$ ) na parte aérea de leguminosas perenes, bianuais e anuais de verão, em Ituporanga, SC.

\begin{tabular}{ccc}
\hline & Matéria & Nitrogênio \\
Leguminosa & verde & total
\end{tabular}

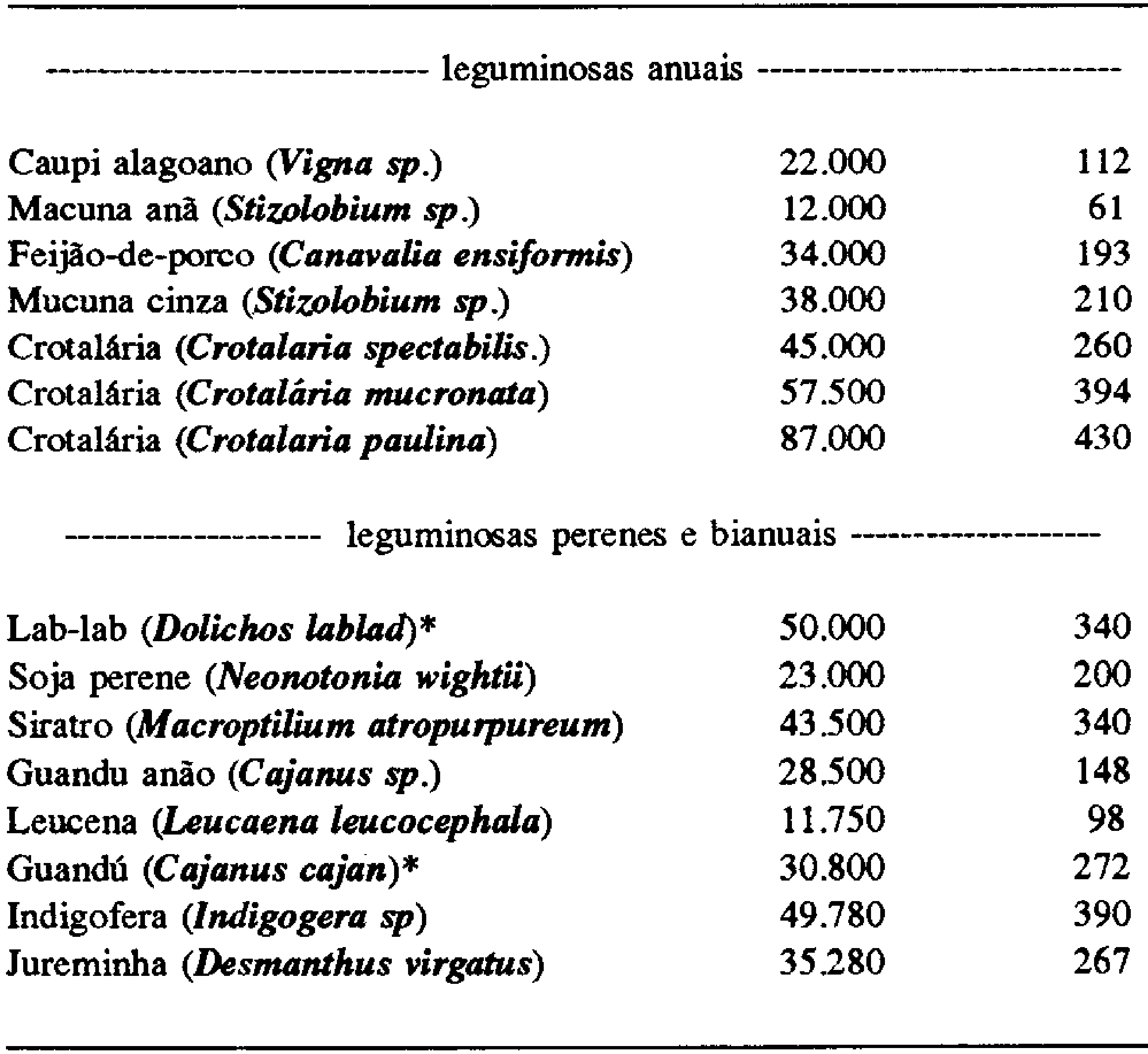

* Espécies de ciclo bianual.

Fonte: AMADO \& ALMEIDA (1987).

A utilidade das leguminosas se torna ainda maior, quando se considera a baixa produtividade dos rebanhos do Sul do Brasil, entre 30 e $50 \mathrm{~kg} / \mathrm{ha}$ ano para carne e 1100 a $1300 \mathrm{~kg} / \mathrm{vaca} /$ ano para leite. Embora não deva ser desconsiderado o baixo padrão racial, que limita o teto de produtividade, a principal causa dos baixos índices acima apresentados, se deve a deficiente alimentação dos animais, baseada fundamentalmente no uso de pastagens nativas, que em muitas propriedades compбem 80 a $90 \%$ da área destinada à bovinocultura. Estas pastagens são formadas predominantemente por gramíneas dos gêneros Axonopus e Paspalum, de baixa digestibilidade ( 37 a $42 \%$ ) e, por isso, não chegam a suprir $50 \%$ das necessidades nutricionas dos animais na maior parte do ano, exigindo suplementação tanto em proteína e matéria seca como em nutrientes digetíveis totais (NDT). Embora em algumas propriedades envolvidas com a atividade leiteira, seja feita a suplementação de volumoso 
no cocho, a forragem fornecida é de baixo valor nutritivo e, assim, a alimentação dos animais continua deficitária (INSTITUTO ..., 1987; PILLAR et al., 1985; RAMOS, 1987).

Considerando os altos custos de produção do leite no sistema que utiliza suplementação de ração balanceada $e$ da instabilidade no preço de venda do produto, a utilização de pastos consorciados de gramíneas e leguminosas perenes pode ser uma alternativa viável para as pequenas propriedades. Isto seria possível principalmente para o litoral Catarinense e litoral e Depressão Central e Oeste do Planalto do Rio Grande do Sul e Noroeste do Paraná, pois nestas regióes as condiçóes climáticas permitem o cultivo tanto de gramíneas como de leguminosas perenes de verão (HILLESHEIN et al., 1987; HUTTON, 1979; SKERMAN, 1977; BOIN, 1986; VETTERLE et al., 1986).

Resultados experimentais obtidos em outras regióes do Brasil e do mundo demonstram que espécies de gramíneas e leguminosas de verão consorciadas são capazes de produzir forragem em qualidade e quantidade suficiente para manter produções de 250 a $500 \mathrm{~kg} / \mathrm{ha} /$ ano de carne (Tabela 2) e de 12 a $14 \mathrm{~kg} / \mathrm{vaca} /$ dia de leite ou ainda maiores (BOIN, 1986; VILLELA et al., 1981; FAVORETTO et al., 1985).

Tabela 2 - Produção anual de carne em pastagens de gramíneas e leguminosas consorciadas.

\section{Pastagem}

Carne

$\mathrm{kg} / \mathrm{ha} / \mathrm{ano}$

Referência

\section{Colonião + centrosema}

(Panicum maximum + Centrosema pubescens)

Colonião + centrosema

(Panicum maximum + Centrosema pubescens)

Gramíneas + leguminosas

Coloniāo + centrosema $1^{\Omega}$ ano

(Panicum maximum + Centrosema pubescens)

Colonião + centrosema $4^{\mathfrak{l}}$ ano

(Panicum maximum + Centrosema pubescens)

Gramíneas $61 \%+$ leguminosas $39 \%$

Pangola + centrosema

(Digitaria decumbes + Centrosema pubescens) 410

Colonião + kuzdu

(Panicum maximum + Pueraria phaseoloides)

Capim-elefante + kudzu

(Pennisetum purpureum + Pueraria phaseoloides)

Colonião + kuzdu

(Panicum maximum + Pueraria phaseoloides)

Pangola + leucena

(Digitaria decumbes + Leucaena leucocephala)

Pangola + centrosema

(Digitaria decumbes + Centrosema pubescens)

Pangola + soja perene

(Digitaria decumbes + Neotonia wightii)

$\begin{array}{ll}268 & \text { MARIOT \& DAVIES (1958) } \\ 395 & \text { GROF \& HARDING (1970) } \\ 255 & \text { TEITZEL et al. (1974) } \\ 928 & \text { MELLOR et al. (1974) } \\ 560 & \text { MELLOR et al. (1974) } \\ 373 & \text { ALCANTARA et al. (1979) } \\ 410 & \text { ARONOVICH et al. (1970) } \\ 725 & \text { TREVIÑO (1979) } \\ 547 & \text { TREVIÑO (1979) } \\ 542 & \text { TREVIÑO (1979) } \\ 585 & \text { TREVIÑO (1979) } \\ 635 & \text { TREVIÑO (1979) } \\ 647 & \text { TREVIÑO (1979) }\end{array}$

Fonte: TEITZEL \& BURT (1976), BOIN (1986); TREVIÑO (1979).

\section{CAPACIDADE PARA FIXAÇÃO SIMBIÓTICA DE NI- TROGENIO}

Algumas vezes é apresentado que as leguminosas de verão não possuem potencial para fornecer nitrogênio em quantidades suficientes para manter o teor proteico de pastagens consorciadas, como ocorre com as leguminosas de inverno, entre as quais podem ser citados os trevos. No entanto, conforme pode ser observado na Tabela 3, o nitrogênio fixado por diversas leguminosas de verão é suficiente para produções de proteína bruta na forragem, equivalentes àquelas obtidas com a gramínea em cultura estreme fertilizada com a dose máxima de $200 \mathrm{~kg} / \mathrm{ha} / \mathrm{ano}$ de nitrogênio recomendada por COMISSÃO... (1989), para pastagens de gramíneas na região Sul. Com isto, torna-se bastante discutível a opção pela pastagem de gramínea em cultura estreme, pois este sistema exige maior investimento e maior custo de produção por unidade de animal produzido, resultando portanto, em maior taxa de risco para a atividade (BOIN, 1986).

Além de mais econômico, o suprimento de nitrogênio para algumas pastagens de gramíneas pode ser mais eficiente quando feito via leguminosa do que quando via fertilizante nitrogenado, pois a concentração do elemento na gramínea consorciada pode ser superior àquela encontrada na gramínea em cultura estreme, mesmo sendo esta adubada com a dose .máxima de $200 \mathrm{~kg} /$ ha de nitrogênio recomendada por laboratórios oficiais de análise de solo para a Região Sul (Tabela 4) (SKERMAN, 1977; BOIN, 1986; COMISSÃO ..., 1989).

Este potencial para fixação simbiótica de nitrogênio também pode ser aproveitado para a diminuição dos custos de lavouras. Isto seria possível pela diminuição ou mesmo eliminação do uso de fertilizantes nitrogenados, que, quando em falta, são os que mais restringem a produtividade dos cereais. Em alguns países, como Austrália e Nova Zelândia, grande parte do nitrogênio utilizado pelos cereais é proveniente da fixação simbiótica de nitrogênio mediante o cultivo estratégico de leguminosas. Entretanto, para que tenham um rápido estabelecimento e desenvolvimento vegetativo adequado que lhes possibilite promover as melhorias esperadas no solo e fixar nitrogênio de acordo com o seu potencial, as leguminosas devem nodular eficientemente. 
Tabela 3. Dose de nitrogênio equivalente, estimada para a gramínea em cultura estreme produzir a mesma quantidade de proteína bruta que a consorciação gramínea-leguminosa.

Consorciação

Equivalente $\mathbf{N}$ fertilizante kgha

Pasto negro + siratro

(Paspalum plicatum + Macroptilium atropurpureum)

Pangola + soja perene ou desmódio

(Brachiaria mutica + Neonotonia wightii c.v. Tinaroo ou

c.v. Greenleaf ou Desmodium sp.)

Colonião + galactia

(Panicum spp. + Galactia striata)

Colinão + siratro

(Paricum sp. + Macroptilium atropurpureum)

Colinião + estilosantes

(Panicum sp. + Stylosanthes guianensis)

Colonião + desmódio

(Panicum spp + Desmodium intortum c.v. Greeenleaf)

Coloniāo + soja perene

(Panicum spp + Neonotonia wightii)

Jaraguá + centrosema

(Hyparrhenia rufa + Centrosema pubescens)

Jaraguá + soja perene

(Hyparthenia rufa + Neonotonia wightii)

100 a 225

138

Fonte: CARVALHO (1986).

Tabela 4. Efeito da adubação nitrogenada e da consorciação no teor de nitrogênio do capim colonião (Média de 3 anos).

\begin{tabular}{|c|c|c|c|}
\hline Tratamentos & $\mathbf{N}(\%)$ & Tratamentos & $\mathrm{N}(\%)$ \\
\hline \multicolumn{2}{|c|}{ - } & \multicolumn{2}{|l|}{$B^{*}$} \\
\hline $0 \mathrm{~kg} / \mathrm{ha}$ de $\mathrm{N}$ & 1,45 & Okg/ha de $N$ & 1,18 \\
\hline $74 \mathrm{~kg} / \mathrm{ha}$ de $\mathrm{N}$ & 1,44 & $60 \mathrm{~kg} / \mathrm{ha}$ de $\mathrm{N}$ & 1,13 \\
\hline $150 \mathrm{~kg} / \mathrm{ha} \mathrm{de} \mathrm{N}$ & 1,47 & $120 \mathrm{~kg} / \mathrm{ha}$ de $\mathrm{N}$ & 1,19 \\
\hline $225 \mathrm{~kg} / \mathrm{ha}$ de $\mathrm{N}$ & 1,67 & $180 \mathrm{~kg} / \mathrm{ha}$ de $\mathrm{N}$ & 1,29 \\
\hline $\begin{array}{l}\text { Estilosantes } \\
\text { (Stylosanthes sp.) }\end{array}$ & 1,62 & $240 \mathrm{~kg} / \mathrm{ha}$ de N & 1,37 \\
\hline $\begin{array}{l}\text { Galáctia } \\
\text { (Galactia striata) } \\
\text { Soja perene }\end{array}$ & 1,76 & $\begin{array}{l}\text { Siratro } \\
\text { (Macroptilium atropurpureum) } \\
\text { Galáctia }\end{array}$ & 1,29 \\
\hline $\begin{array}{l}\text { (Neonotonia wightii) } \\
\text { Siratro } \\
\text { (Macroptilium atro- }\end{array}$ & 1,67 & (Galactia striata) & 1,25 \\
\hline $\begin{array}{l}\text { purpureum) } \\
\text { Centrosema }\end{array}$ & 1,78 & & \\
\hline (Centrosema sp.) & 1,79 & & \\
\hline
\end{tabular}

*A e B = Representam fontes de dados independentes Fonte: BOIN (1986).
Da mesma forma, para que se transformem em pastagens bem sucedidas e, assim, possam manter o sistema pastagem-animal continuamente produtivo, as leguminosas devem nodular intensa, contínua e eficientemente de modo que a sua simbiose possa fixar nitrogênio em quantidade suficiente para manter elevado o teor proteico da pastagem, principal função da leguminosa no sistema (HUTTON, 1964; TREVIÑO, 1979). Uma das alternativas para atingir uma nodulação com tais características é o melhoramento genético voltado para a obtenção de plantas com hábito de crescimento rizomatoso ou estolonífero, pois estas características permitem a renovação contínua das raízes e, por conseguinte, da nodulação. Além da maior fixação de nitrogênio este tipo de hábito possibilita que a leguminosa se mantenha densa e com alta produção de forragem mesmo sob pastejo contínuo, o que é muito importante para as pequenas propriedades onde deve ser buscada a máxima rentabilidade por unidade de área (HUTTON, 1964; BOIN, 1986; HUTTON, 1979; HUTTON, 1977).

Muitas vezes, no entanto, o rizobiologista se depara com uma leguminosa já melhorada e, por isso, suas chances de obter combinações leguminosa-rizóbio eficientes na fixação simbiótica de nitrogênio se restringem ao aproveitamento da variabilidade genética do rizóbio. A dificuldade se torna ainda maior, quando a capacidade para fixação simbiótica de nitrogênio é pouco considerada em programas de introdução e/ou seleção de novos genótipos (NORRIS, 1967).

\section{CARACTERÍSTICAS DA FIXAÇÃO SIMBIÓTICA DE NITROGÊNIO}

\section{Relaçðes planta-bactéria}

A falta de vigor inicial das plantas que, com freqüência, é utilizada como referência para o descarte de genótipos e/ou introduções, se torna um critério pouco adequado quando os requerimentos da leguminosa quanto ao rizóbio não são considerados, pois os diferentes graus de afinidade ou especificidade entre a planta e o rizobio podem determinar nodulação precária ou mesmo inexistente nestas leguminosas que, em conseqüência, apresentarão estabelecimento muito lento e produção de forragem limitada (NORRIS, 1967; TRINICK, 1982; DATE, 1976).

Embora a especificidade planta-bactéria houvesse sido demonstrada há praticamente 50 anos, por muito tempo ainda perdurou a concepção de que a inoculação de leguminosas de verão não seria necessária devido a sua promiscuidade para nodulação com estirpes nativas (HALLIDAY, 1979). Porém, com a difusão de um maior número de espécies, ficou evidenciado existirem muitas lacunas nos conhecimentos sobre seus requerimentos, quanto ao rizóbio (TRINICK, 1982). Estudos recentes confirmaram a ocorrên- 
cia de especificidade na simbiose para diversas leguminosas tropicais anteriormente tidas como promíscuas, tornando evidente a existência de subgrupos diferenciados entre espécies e até entre cultivares dentro da mesma espécie (TRINICK, 1982; BOWEN \& KENNEDY, 1961; HALLIDAY, 1979).

\section{A especificidade hospedeira e a eficiência simbiotica.}

A capacidade para nodulação recíproca entre espécies do grupo caupi de fato é muito comum e a mesma pode ocorrer até entre os outros grupos de inoculação, embora, neste caso, freqüentemente seja ineficiente. Esta menor especifidade das leguminosas de verão do grupo caupi quando comparada com as leguminosas de clima temperado de outros grupos, exige ainda maior atenção do rizobiologista, pois a presença de nódulos não significa necessariamente que a simbiose esteja sendo eficiente e que, por isso a inoculação de leguminosas de verão seria uma prática desnecessária (TRINICK, 1982; DATE, 1976; HALLIDAY, 1979).

As discordâncias observadas em literatura sobre o assunto, segundo DATE (1976), podem ser atribuídas a não distinção, nos trabalhos antigos, entre a capacidade para nodulação e a eficiência da simbiose leguminosa-rizóbio. Ante os muitos exemplos de especificidade já comprovada, o autor aponta a necessidade de abandonar a idéia de que todas ou a maioria das leguminosas tropicais classificadas como do grupo caupi não necessitam de rizóbio específico. As divergências se tornam explicáveis quando se considera que apesar da planta hospedeira ter influência dominante na determinação de qual a estirpe a induzir a nodulação, os fatores ambientais, principalmente $\mathrm{pH}$ e temperatura, atuam conjuntamente com o genótipo e as estirpes, influindo decisivamente no processo de infecção. Destaca ainda o autor que, a especificidade poderá se manifestar em todas as fases da associação, culminando na eficiência da fixação de nitrogênio.

Devido a complexidade das relações entre leguminosa e o rizóbio e a necessidade de distinção entre capacidade para nodulação e eficiência simbiótica, DATE (1976), propõe o reagrupamento das leguminosas, com base na sua eficiência simbiótica para com as estirpes nativas de rizóbio, em três grupos: $\mathrm{PE}=$ promíscuo e eficiente, $\mathrm{PI}=$ promíscuo, mas freqüentemente ineficiente e $S=$ específico. No entanto, estes grupos não são estanques, pois o proprio autor relata que mesmo incluídas no grupo promíscuo e eficiente, determinadas leguminosas tropicais não formarão simbiose eficiente com todas as estirpes nativas.

\section{Origem da especificidade leguminosa-riz6bio}

Qualquer estudo relacionado com a inoculação de leguminosas e especificidades entre leguminosas e rizobio, conforme DATE (1976), deve levar em conta a origem da leguminosa e do seu rizóbio associado. Em resposta a mudanças ambientais, as leguminosas foram mudando progressivamente de forma, desde árvores grandes, até arbustos e ervas, com o rizóbio evoluindo conjuntamente, até a formação de associaçб̃es simbióticas bastante especializadas, como no caso dos trevos e vicas, consideradas como espécies altamente evoluídas. Entretanto, devido as variações de clima e solo durante o processo de evolução, nem todas as leguminosas de verão existentes estão adaptadas a baixa fertilidade dos solos tropicais e subtropicais e, também, algumas leguminosas de clima temperado apresentam resposta diferenciada aos solos férteis e rizobios de crescimento rápido (DATE,1976; NORRIS, 1967; NORRIS \& DATE, 1976).

\section{Melhoramento genético das plantas e especificidade na simbiose}

Outro fator a ser considerado no estudo sobre fixação de nitrogênio em leguminosas de verão, diz respeito ao melhoramento genético, pois o mesmo pode alterar drasticamente as relaçðes planta-bactéria. Apesar de o melhoramento genético para aumentar a fixação simbiótica de nitrogênio ser uma possibilidade bastante concreta, face aos resultados obtidos com leguminosas de grãos, poucas são as pesquisas feitas com leguminosas forrageiras de verão. É digno de nota, entretanto, o desenvolvimento da cultivar "Belalto" demonstrando que mesmo entre espécies com marcante especificidade hospedeira, como a Centrosema pubescens do qual esta cultivar foi originada, é possivel desenvolver genótipos com características agronômicas superiores e, ao mesmo tempo, com alta capacidade para fixação de nitrogênio (SIGURBJORNSSON, 1984; BOIN, 1986; PEREIRA, et al, 1991; TEITZEL \& BURT, 1976). Visando o melhoramento genético para caracteres específicos, muitas vezes a capacidade para fixação simbiótica de nitrogênio destas plantas não é suficientemente aproveitada. Como conseqüência, menores serão as possibilidades de se obter combinaçð̌es planta-bactéria autosuficientes em nitrogênio, pois com o estreitamento da sua variabilidade genética, a leguminosa torna-se, progressivamente, mais específica quanto ao riz6bio (NORRIS, 1967; DATE, 1976; NUTMAN, 1976).

Assim, como não é possível prever o comportamento das estirpes nativas quando da introdução de leguminosas de verão em novas áreas, da necessidade de garantir o sucesso no estabelecimento destas plantas nestas áreas e, ainda, do desenvolvimento de novos genótipos, através do melhoramento genético, torna-se imprescindível tanto a reavaliação das estirpes dos bancos de germoplasma como a seleção contínua de novas estirpes. Com isto serão asseguradas combinaçðes leguminosas-rizobio eficientes na fixação de nitrogênio para cada local desejado de maneira que as leguminosas de verão possam realmente expressar o seu potencial de utilização na alimentação animal e nos programas de uso, manejo e conservação do solo nos quais forem incuídas 
(DATE, 1976; SKERMAN, 1977; MIRANDA et al., 1985; PRIMAVESI, 1985).

\section{CONCLUSÕES}

As condições climáticas em diversas sub-regiơes do Sul do Brasil permitem o cultivo de leguminosas de verão durante a maior parte do ano e em alguns locais o ano todo.

A diversidade de espécies entre as leguminosas de verão possibilitam opçðes para a sua inclusão em programas de rotação de culturas em solos degradados pelo manejo inadequado.

Pelos seus altos teores de nitrogênio, quando consorciadas com gramíneas, as leguminosas de verão podem constituir pastagens de alto valor nutritivo, sustentando pecuária tanto de corte quanto leiteira, com altos índices de produtividade e a baixos custos.

Para que produzam adequadamente, as leguminosas de verão devem nodular eficientemente, porém, freqüentemente isto não ocorre, pois diversas espécies e mesmo cultivares de uma mesma espécie apresentam requerimentos específicos quanto ao rizóbio.

Para garantir a disponibilidade de inoculantes específicos a cada leguminosa e local de interesse, deve-se proceder o isolamento contínuo de novas estirpes de rizobio, paralelamente com a reavaliação periódica das estirpes disponíveis em bancos de germoplasma.

\section{REFERÊNCIAS BIBLIOGRÁFICAS}

AMADO, T.J.C., ALMEIDA, E.X. de. Adubação verde de verão para o Alto Vale do Itajar. Florianópolis: EMPASC, 1987.6 p. (Pesquisa em Andamento, 73).

AMADO, T.J.C., ALMEIDA, E.X. de., TORRES, L. Cobertura do solo e adubação verde na cultura da cebola. Ituporanga: EMPASC, 1986. 16 p. (Projeto de pesquisa não publicado).

BOIN, C. Produção animal em pastos adubados. In: MATTOS, H.B., WERNER, J.C., YAMADA, T., MALAVOLTA, E. ed. Calagem e adubação de pastagens. Piracicaba: POTAFOS, 1986. p. 386-419.

BOGDAN, A.V. The legumes, In: BOGDAN, A.V. Tropical pasture and fodder plants. London: Longman. 1977. p. 302-317.

BOWEN, G.D., KENNEDY, M.M. Heritable variation in nodulation of Centrosema pubescens Benth. Queensland Journal of Agricultural Science, Brisbane, v. 18, p. 161-170, 1961.

CARVALHO, M.M. Fixação biológica como fonte de nitrogénio para pastagens. In: MATTOS, H.B., WERNER, J.C., YAMADA, T., MALAVOLTA, E., eds. Calagem e adubação de pastagens, Piracicaba: POTAFOS, 1986. p. 383-410.

CIAT. Informe CIAT: Programa de pastos tropicales. Cali: CIAT, 1980. p. 69-87.
COMISSÃO DE FERTILIDADE DO SOLO - RS/SC. Recomendações de adubação e calagem para os Estados do Rio Grande do Sul e Santa Catarina. 2 ed. Passo Fundo: SBCS-Nácleo Regional SulEMBRAPA-CNPT, 1989. 128 p.

DALLA ROSA, A. Práticas mecanicas e culturais na recuperaçăo de características fisicas de solos degradados pelo cultivo-solo Santo Angelo (Latossolo Roxo Distrofico). Porto Alegre-RS. 136 p. Tese (Mestrado em Agronomia-Solos) - Curso de Pós-graduação em Agronomia, Departamento de Solos, UFRGS. 1981.

DATE, R.A. Especificidad en la simbiosis Rhizobium/eguminosa. In: REUNION LATINOAMERICANA SOBRE RHIZOBIUM, 8., 1976, Cali, Anales... Cali, CIAT, 1976. p. 42-80.

FAVORETTO, V., REIS, R.A., VIEIRA, P. de. F., MALHEIROS, E.B. Efeito da adubação nitrogenada ou de leguminosas no ganho de peso vivo de bovinos em pastagens de capim-coloniazo. Pesquisa Agropecuária Brasileira, Brasília, v. 20, n. 4, p. 475-482, 1985.

FRANCO, A.A., SOUTO, S.M. Contribuição da fixação biológica de $\mathrm{N}_{2}$ na adubação verde. In: FUNDAÇÃo CARGILL. Adubação verde no Brasil. Campinas: 1984. p. 199-215.

HALLIDAY, J. Field responses by tropical forage legumes to inoculation with Rhizobium. In: SANCHEZ, P.A., TERGAS, L.E. Pasture production in acid soils of the tropics. Cali: CIAT. 1979. p. 123-138.

HILleShein, A., PILLAR, V. de. P., AGOSTINI, I., et al. Avaliação do sistema de produção de leite da Estação Experimental de Itajar-EMPASC, 1980 a 1983. Florianópolis, EMPASC, 1987. 59 p. (EMPASC. Documentos, 78).

HUTTON, E.M. Plant breeding and genetics. In: CSIRO. Cunninghan Laboratory. Some concepts and methods in subtropical pasture research. Hurley: CAB, 1964. p. 79-92. (Commonwealth Bureau of Pasture and Field Crop Bulletin, 47).

HUTTON, E.M. Selection and breeding of tropical legumes. In: SKERMAN, P.J., ed. Tropical forage legumes. Rome: FAO, 1977. p. 174-185. (FAO Plant Production and Protection Series, 2).

HUTTON, E.M. Problems and sucesses of legume-grass pastures, especially in tropical Latim America. In: SANCHEZ, P.A., TERGAS, L.E. Pasture production in acid soils of the tropics. Cali: CIAT. p. 81-93. 1979.

INSTITUTO DE PLANEJAMENTO E ECONOMIA AGRÍCOLA DE SANTA CATARINA Sintese Anual da Agricultura de Santa Catarina. Florianópolis: v. 1, p. 114-126, 1987.

MAZUCHOWSKI, J., DERPSCH, R. Guia de preparo do solo para culturas anuais mecanizadas. Curitiba: ACARPA, 1984. 68 p.

MIRANDA, C.J.B., SEIFFERT, N.F., SOUTO, S.M. Especificidade e competitividade de estirpes de Rhizobium em centrosema sob condiçðes controladas. Pesquisa Agropecuária Brasileira, Brasília, v. 20, n. 10, p. 1157-1161, 1985.

MIYASAKA, S. Histórico de estudos de adubação verde, leguminosas viáveis e suas características. In: FUNDAÇÃO CARGILL. Adubação verde no Brasil. Campinas, Fundação Cargil 1984. p. 64-123.

NORRIS, D.O. The intelligent use of inoculants and lime pellecting for tropical legumes. Tropical Grasslands, Brisbane, v. 1, n. 2, p. 107-127, 1967. 
NORRIS, D.O., DATE, R.A. Legume bacteriology. In: SHAW, N.H., BRYAN, W.W. ed., Tropical pasture research, principles and methods. Hurley: CAB, 1976. p. 234-274. (Commonwealth Bureau of Pastures and Field Crops Bulletin, 51).

NUTMAN, P.S. Field experiments on nitrogen fixation by nodulated legumes, In: NUTMAN, P.S. ed. Symbiotic nitrogen fixation in plants. Cambridge: University Press, 1976. p. 211-237.

PEREIRA, P.A.A., MIRANDA, B., WOLYN, et al. Genotipic variability and combining ability for nodule number in common bean. Madison, University of Wisconsin. 1991. 2 p.

PILlAR, V. de P., HILleshEIN, A., AGOSTINI, I. Acompanhamento de sistemas reais de produçăo de leite na regiāo do Alto Vale do Itajaf em Santa Catarina. Florianópolis: EMPASC, 1985. 31 p. (EMPASC Documentos, 50).

PRIMAVESI, O. A compactação de solos agricolas. Piracicaba: POTAFOS, 1985. p. 1-3.

RAMOS, M.G. Diagnóstico, análise e melhoramento de sistemas reais de produção de leite no Vale do Itajal e Litoral de Santa Catarina. Itajaí: EMPASC, 1987. 31 p. (Relatório de pesquisa não publicado).

SANTA CATARINA, Gabinete de planejamento e coordenação geral. Sub-chefia de estatística, geografia e informática. Atlas de Santa Catarina. Rio de Janeiro: Aerofoto Cruzeiro, 1986. p. 38.
SKERMAN, P.J. The role of legumes in agriculture. In: SKERMAN, P.J., ed. Tropical forage legumes. Roma: FAO, 1977. p. 1-9. (FAO Plant Protection Series).

SIGURBJORNSSON, B. Foreword. In: HARDARSON, G., LIE, T. A. ed., Breeding legumes for enhanced dinitrogen fixation. Dordrecht: Martinus Nijhof/W. Junk. p. 7-8. 1984.

TEITZEL, J.K., BURT, R.L. Centrosema pubenscens in Australia. Tropical Grasslands. Brisbane, v. 10, n. 1, p. 5-14, 1976.

TREVIÑO, R.G. Beef production in the humid tropics of Mexico. In: SANCHEZ, P.A., TERGAS, L.E. Pasture production in acid soils of the tropics. Cali: CIAT. 1979. p. 289-309.

TRINICK, M.J. Host-Rhizobium associations. In: VINCENT, J.M. ed. Nitrogen fixation in legumes. Sidney: Academic Press, 1982, p. 111-122.

VETTERLE, C.P., HILLESHEIN, A., AGGELER, K.E., et al. Descrição do sistema de produção de leite na Estação Experimental de Itajaf-EMPASC. Florianópolis: EMPASC. 1986. 44 p. (EMPASC Documentos, 21).

VILLELA, H., TEIXEIRA FILHO, A.G., NASCIMENTO JÚNIOR, D., et al. Efeito de pastagem com leguminosas e de pastagem com uréia sobre o desempenho de novilhos. Revista da Sociedade Brasileira de Zootecnia, Viçosa, v. 10, n. 1, p. 78-87, 1981. 